\title{
Pitfalls in labelled leukocyte scanning
}

\author{
H HODGSON, DM, FRCP, M RODDIE, MRCP, FRCR
}

\begin{abstract}
Radiolabelled leukocyte scanning is a valuable tool in the diagnosis and management of inflammatory bowel disease (IBD). As well as determining the presence or absence of disease and its complications, the degree of inflammation may be quantified either visually or numerically following four day fecal collection. The authors discuss the labelling techniques currently in use and the appearance of IBD using both ${ }^{111}$ Indium and ${ }^{99 \mathrm{~m}}$ Technetium as the labelling isotope. The advantages and disadvantages of each technique are compared. Certain diagnostic pitfalls and causes of false-positive results including radiation enteritis, nonsteroidal anti-inflammatory drug ingestion and intra- and extra-abdominal sepsis are discussed in full, and it is shown that in most cases good labelling technique, careful imaging and awareness of alternative mechanisms for leukocyte appearance in the gastrointestinal tract will ensure correct interpretation of these scans. Can J Gastroenterol 1990;4(7):331-335
\end{abstract}

Key Words: Crohn's disease, Diagnosis, Leukocyte scanning, Ulcerative colitis

\section{Ecueils de la scintigraphie aux leucocytes radiomarqués}

RESUME: La scintigrapie aux leucocytes radiomarqués est un outil précieux dans le diagnostic et le traitement des maladies inflammatoires de l'intestin (MII). En plus de déterminer la présence ou l'absence de la maladie et ses complications, il est possible de quantifier le degré d'inflammation visuellement ou numériquement après prélèvement d'échantillons de selles sur quatre jours. Les auteurs décrivent les techniques de radiomarquage présentement utilisées et l'apparence des MII lorsque l'indium 111 et le technétium $99 \mathrm{~m}$ sont les radioisotopes utilisés. Les avantages et inconvénients de chaque technique sont comparés. Les auteurs examinent certains écueils diagnostiques et les situations causant des résultats faussement positifs. Parmi eux figurent l'entérite radique, les anti-inflammatoires non stéroïdiens, les septicémies intra et extra-abdominales. Dans la majorité des cas, une bonne technique de radiomarquage, la lecture attentive de l'image et la connaissance des mécanismes pouvant expliquer l'apparence des leucocytes dans les voies gastro-intestinales garantit l'interprétation correcte des examens.

Hammersmith Hospital, London, United Kingdom

Correspondence and reprints: Dr H Hodgson, Royal Postgraduate Medical School, Hammersmith Hospital, Du Cane Road, London, W12 OHS, United Kingdom

\section{$\mathrm{R}$} ADIOLABELLED LEUKOCYTE SCAN. ning is a valuable tool in the diagnosis and management of inflammatory bowel disease (IBD). In this article the appearance of IBD and its complica-

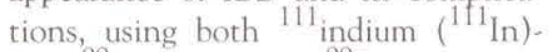
and $99 \mathrm{~m}_{\text {technetium }}\left({ }^{99 \mathrm{~m}_{\mathrm{T}}} \mathrm{T}\right)$-labelled leukocytes, have been described. Potential diagnostic pitfalls and causes of false-positive results are discussed. In most cases good labelling technique and awareness of alternative mechanisms for leukocyte appearance in the gastrointestinal tract will ensure correct interpretation of these scans.

\section{${ }^{11}$ INDIUM \\ ${ }^{111}$ In-labelled leukocyte scanning} involves separation of autologous leukocytes from approximately $60 \mathrm{~mL}$ venous blood and labelling via a chelate before re-injection into patients. For detecting inflammation in IBD, both mixed leukocytes (granulocytes, lymphocytes and monocytes) or purified granulocytes (in which a density gradient is used to separate granulocytes from mononuclear cells) have been employed. If the patient is neutrophilic (greater than $9 \times 10^{3} / \mathrm{L}$ ), then a mixed leukocyte preparation is satisfactory in most cases. However, low grade inflammation is more likely to be detected with a pure granulocyte 

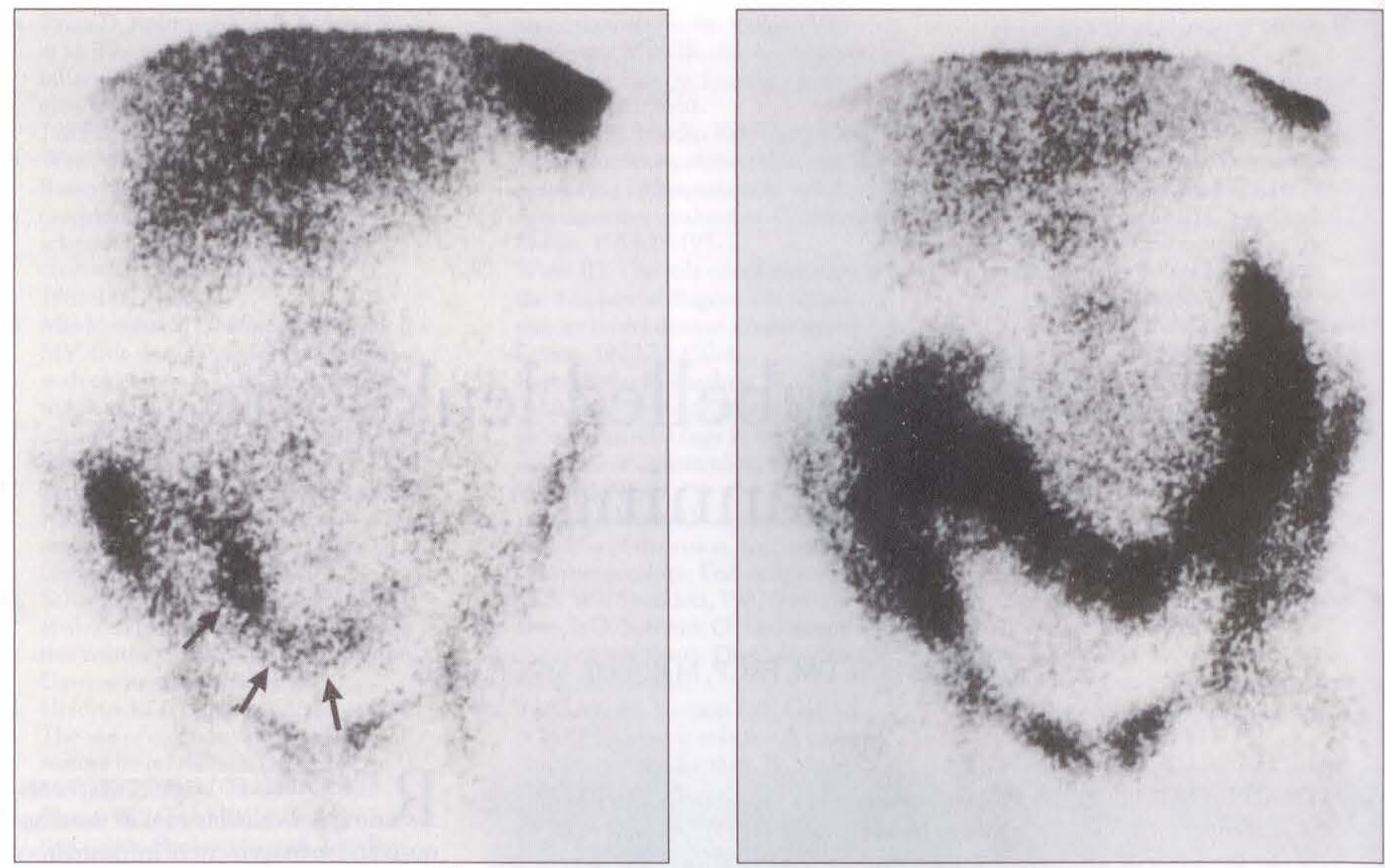

Figure 1) Left Four hours after injection of ${ }^{111}$ indium-tropolonate-labelled granulocytes there is marked activity in the terminal ileum (arrows) of this patient with active Crohn's disease. Right Twenty-four hours after injection this activity has passed into the lumen of the bowel and now lies in the colon

\section{TABLE 1}

\section{Major conditions in which abnormal radiolabelled leukocyte scans have been reported}

Inflammatory bowel disease
Crohn's disease
Ulcerative colitis
Infectious colitis
Salmonellosis
Clostridium difficile colitis
Ischemic colitis
Vasculitis
Radiation enteritis
'Ampicillin' colitis
Obscure gastrointestinal bleeding
Biopsy sites
Abscesses
Uncomplicated surgical anastomoses
Abdominal wounds
Perforating carcinoma of the colon
Graft versus host disease
Diverticulitis
Nonsteroidal anti-inflammatory drug
ingestion

population. Suitable chelating agents for ${ }^{111}$ In include oxine, acetylacetone and tropolonate. In contrast to the former two agents, ${ }^{111}$ In-tropolonate efficiently labels leukocytes in plasma
(1). Maintaining granulocytes in plasma during the preparative procedure, rather than washing them in saline, keeps them in a good physiological state. Activation of granulocytes during the preparative process is manifested as immediate sequestration in the pulmonary vascular bed followed by high liver uptake.

Following re-injection, ${ }^{111}$ In leukocytes are normally distributed and in dynamic equilibrium between the marginating and circulating granulocyte pool. A large fraction (at least onethird) of the marginating granulocyte pool is located in the spleen. Most of the remainder is in the liver and bone marrow (2). There is thus a normal distribution of activity which is most marked in the spleen, less in the liver and least in the bone marrow. Inflammation is recognized as activity seen outside the expected normal distribution. Dynamic scanning data show that migration of labelled cells to areas of inflammation can be detected within 10 mins. Progressive accumulation will occur if there is no drainage from that area, but if gastrointestinal tract inflammation is present, leukocytes migrate through the bowel wall into the lumen and are carried distally in the stream of intestinal fluid or feces. For IBD, this offers the possibility of quantitating disease activity by fecal collection. However, the phenomenon also means that the timing of the scans is critical in gut disease. On ${ }^{111}$ In scans, gastrointestinal activity $4 \mathrm{~h}$ after injec. tion represents the disease site, whereas later, particularly on the next day, activity in the colon may merely represent labelled feces in passage (Figure 1). Twenty-four hour images are, however, valuable in delineating areas of inflammation away from the gut mucosa, particularly in delineating abscesses where there is progressive accumulation of granulocytes over $24 \mathrm{~h}$.

\section{${ }^{99} \mathrm{~m}$ TECHNETIUM}

${ }^{99} \mathrm{~m}_{\mathrm{c}}$ is cheaper and more readily available than ${ }^{111} \mathrm{In}$, and with its short half-life, emits less radiation than ${ }^{111}$ In 

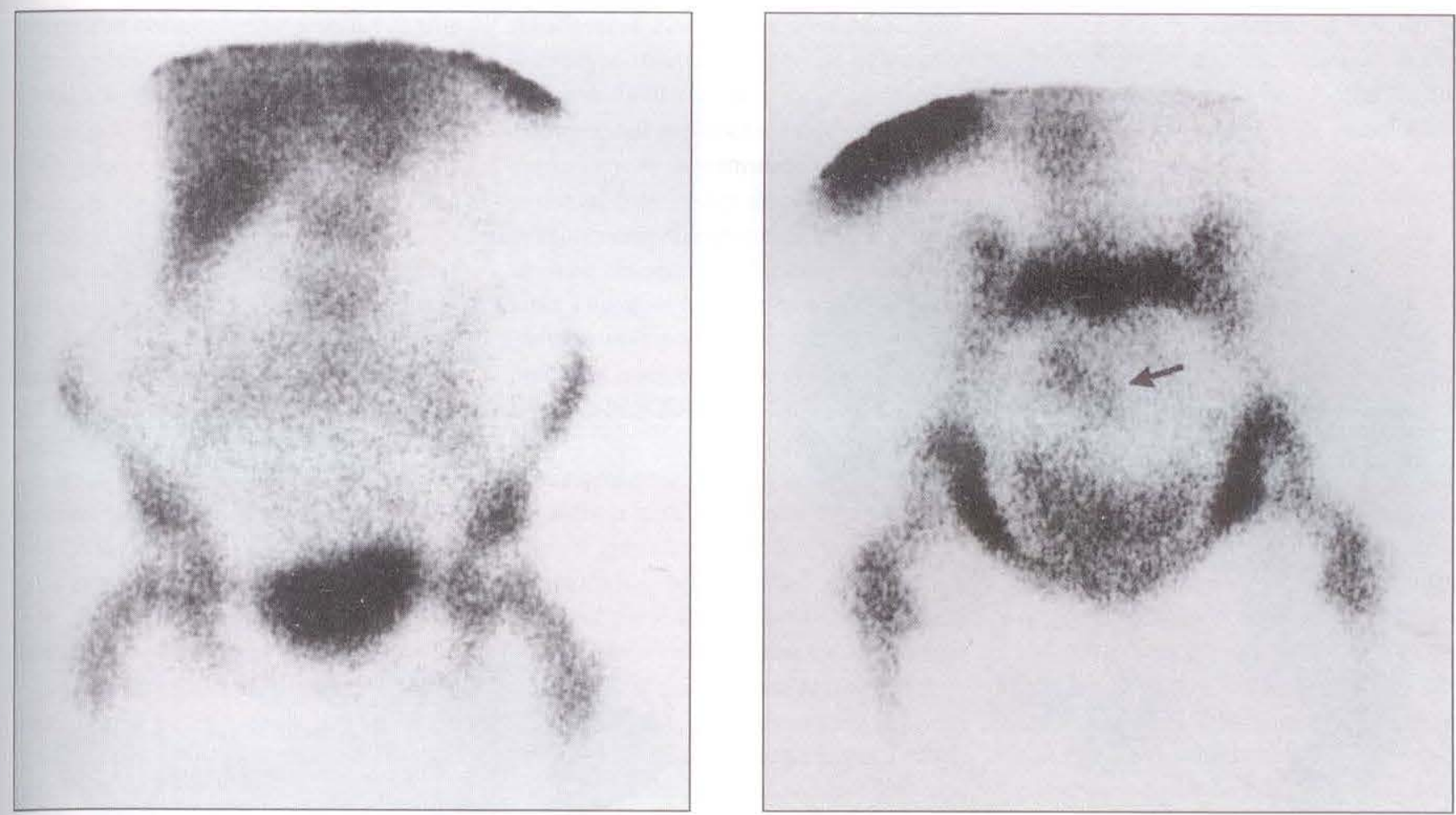

Figure 2) Left Three hours after injection of ${ }^{99 \mathrm{~m}}$ technetium hexamethyl propylene amine oxime-labelled leukocytes, the anterior abdominal image shows no abnormality in this patient with active proctitis because bladder activity obscures the rectum. Right A pelvic outlet view performed immediately afterwards demonstrates rectal activity (arrow) lying behind the bladder

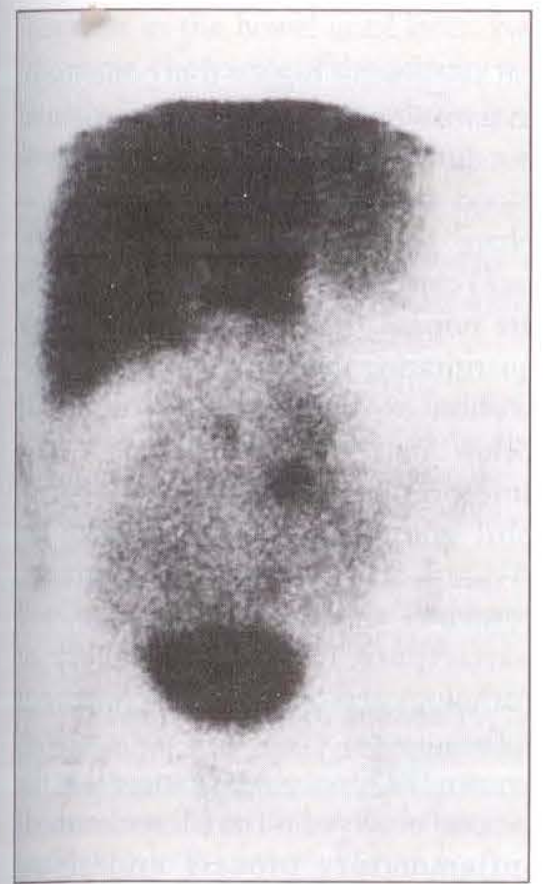

Figure 3) ${ }^{99 \mathrm{~m}}$ Technetium hexamethyl propylene amine oxime-labelled leukocytes $3 \mathrm{~h}$ after injection in a patient with radiation enteritis and abscess formation. Note the $a b$ sence of bone marrow activity in the radiation field, the generalized increase in activity in the pelvis and the two focal areas of activity which represent abscesses when imaging doses are used. The ability of polymorphonuclear leukocytes and monocytes to phagocytose particles has been used by some centres via imaging after ${ }^{99 \mathrm{~m}} \mathrm{~T}$ c-labelled colloid has been added to whole blood in vitro $(3,4)$. Although the method of labelling is undoubtedly less complicated, others have found this technique unpredictable and, in particular, leukocytes which have phagocytosed colloid tend to become activated and sequestered in the lungs immediately following injection (5).

The current most effective means of labelling leukocytes with ${ }^{99 \mathrm{~m}} \mathrm{Tc}$ is via the lipophilic compound hexamethyl propylene amine oxime (HMPAO). HMPAO preferentially labels granulocytes in buffer coat leukocyte preparations, allowing considerable simplification of the labelling procedure (6). However, it is bound less stably than ${ }^{111}$ In-tropolonate, resulting in some elution of the complex, which then undergoes both biliary and urinary excretion. Bladder activity may therefore obscure pelvic inflammation, but this problem can be resolved either by asking the patient to empty the bladder or by performing a pelvic outlet view (Figure 2). After a variable delay, radioactivity enters the gastrointestinal tract, even in normal individuals, reflecting a normal pathway of biliary excretion of the complex - as a result of which faint gastrointestinal images are always apparent $8 \mathrm{~h}$ or so after injection. Occasionally, striking amounts of activity be seen in the gallbladder. Therefore, delayed (longer than $4 \mathrm{~h}$ ) scans after technetium-labelled leukocyte re-injection may give the impression of gastrointestinal tract inflammation where none exists. It is therefore important to image before $4 \mathrm{~h}$ if IBD is suspected when ${ }^{99} \mathrm{~m} \mathrm{Tc}$ HMPAO-radiolabelled leukocytes are used (7).

Alternative means of cell labellingvia monoclonal antibodies to leukocytes - are being explored, but clinical experience with them is limited, and the definition of images obtained does not yet equal that seen with colloid labels. 

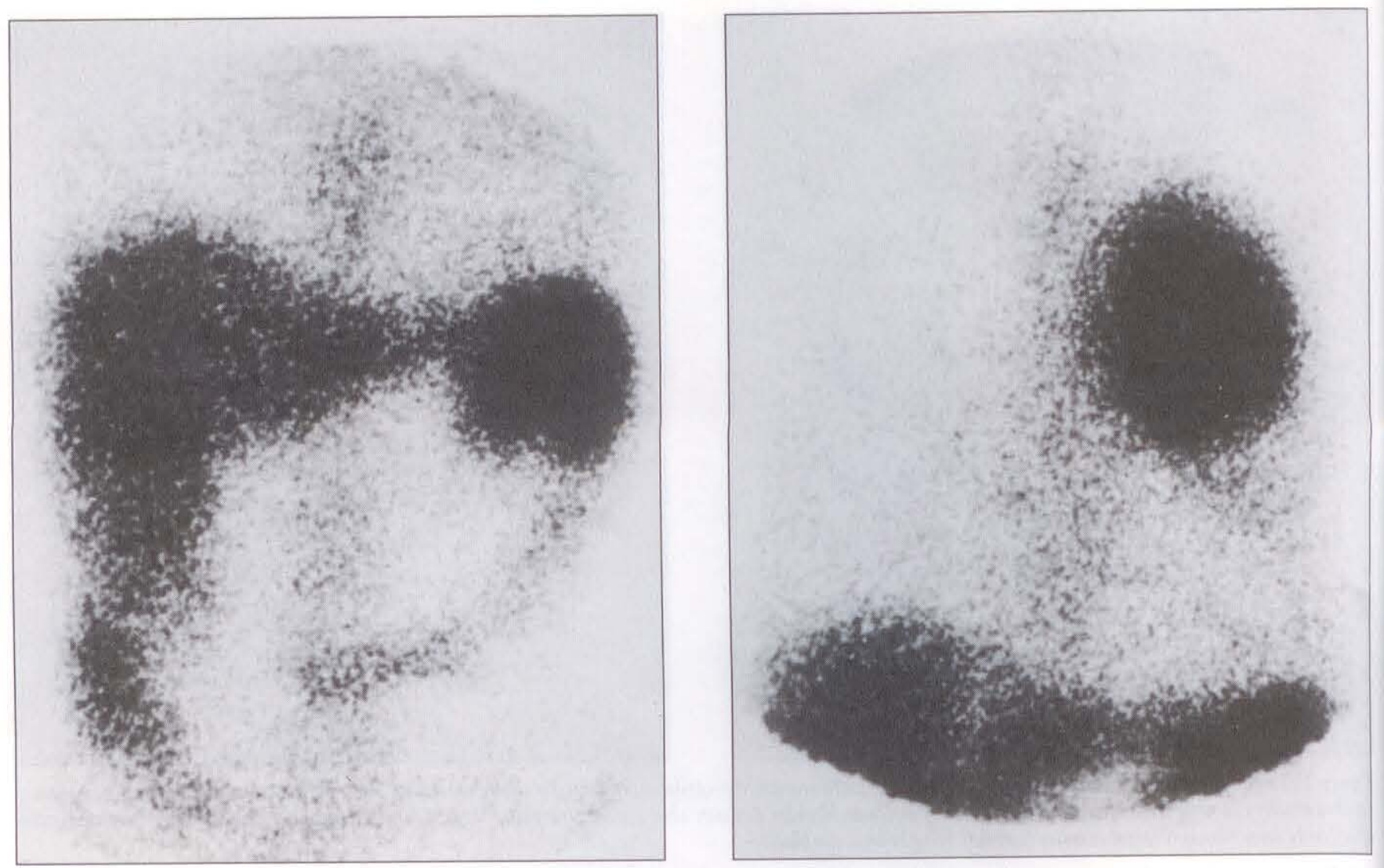

Figure 4) Left Activity is seen in the colon at 24 h in a patient whose 4 h abdominal image was normal. Right The anterior chest image shows accumulation of activity in a huge left upper lobe lung abscess. The colonic activity is a result of swallowing sputum containing labelled leukocytes

\section{IMAGING IN IBD}

Detecting small intestinal inflammation: The superior image resolution obtained with ${ }^{99 \mathrm{~m}} \mathrm{Tc}$ means that the detection of small intestinal disease is significantly better with the ${ }^{99 \mathrm{~m}} \mathrm{Tc}$ HMPAO technique than with ${ }^{111}$ In. During the longer time required for image accumulation with ${ }^{111}$ In, the bowel may move, preventing visualization of a diseased small bowel segment against background activity or obscuring definition. This may be a particular problem if the suspect loop lies over the sacroiliac region where background activity may be high. Also, the diffuse form of small intestinal Crohn's disease, widely but mildly affecting the jejunum, may not be apparent on $4 \mathrm{~h}^{111}$ In scans. Its presence may, however, be inferred from the presence of activity more distally on the ensuing day.

Detecting colonic inflammation: The relatively fixed anatomical relationships of the colon result in greater definition of the extent and presence of colonic inflammation.
When colonoscopic studies have been performed within a short space of time of ${ }^{111}$ In leukocyte scanning, there has been a high correlation between both techniques in defining extent with purified granulocytes (8). A number of authors have drawn attention to discrepancies between the distribution of disease assessed radiologically or at laparotomy, and that shown with mixed leukocyte scans. In some cases these discrepancies reflect late performance of the scan, resulting in an overestimation of disease due to migration of labelled cells. The mobile sigmoid colon presents a potential pitfall in colonic imaging, as this can overlie the right fossa in extreme cases, thus suggesting the presence of ileal inflammation. Under these circumstances oblique views may help.

Limits of detection: In comparative studies in Crohn's disease, leukocyte scanning has proved superior to conventional radiology in detecting disease (9). Positive leukocyte scans can occur when conventional laboratory or clini- cal assessments suggest that patients are in remission. However if disease is mild but diffuse, mild symptoms or abnormal blood tests (elevated creatine phos. phate and erythrocyte sedimentation rate) can occur in patients whose scans are normal. The role of techniques of quantitating inflammation by fecal ex. cretion or other means is discussed below.

Interpreting inflammation: Neutrophil granulocytes, attracted by activated complement components, cytokines and bacterial products, will participate in a wide variety of pathological processes. The presence of inflammation even in a patient with known IBD does not guarantee that the process observed is the (ill understood) inflammatory process underlying chronic IBD. Table 1 lists the major conditions in which abnormal radiolabelled leukocyte scans have been reported.

Radiation enteritis, usually following gynecological or urological malig. nancies, demonstrates a characteristic 
absence of bone marrow activity in the region of the radiation field (Figure 3 ). Otherwise the appearance of this condition may not differ from that seen in IBD, except insofar as the anatomical location usually corresponds to the radiation field.

Patients with arthritis taking nonsteroidal anti-inflammatory drugs (NSAIDs) may demonstrate accumulation of activity in the right iliac fossa at $24 \mathrm{~h}$. This observation is difficult to interpret and the relative contribution of an enteropathy predisposing to arthritis and a direct toxic effect of NSAIDs is unclear. The activity on the $24 \mathrm{~h}$ images has been attributed to diffuse mid or upper small intestinal leakage due to its delayed appearance.

Disease outside of the gastrointestinal tract may cause confusion. Pneumonia, bronchiectasis, and lung abscesses can all result in spillage of labelled leukocytes from the bronchial tree into the esophagus (Figure 4). Hepatobiliary sepsis may also result in false-positive gastrointestinal activity. However these cases can usually be distinguished from IBD since activity is not seen in the bowel until later. Furthermore, the source of the activity will usually be identifiable on whole body scanning before $24 \mathrm{~h}$.

\section{REFERENCES}

1. Danpure HJ, Osman S, Brady F. The labelling of blood cells in plasma with 111-In-tropolonate. $\mathrm{Br}]$ Radiol 1982;55:247-9.

2. Peters AM, Saverymuttu SH, Bell RN, Lavender JP. Quantification of the distribution of the marginating granulocyte pool in man. Scand J Haematol 1985;34:111-20.

3. Scroth HJ, Oberhausen E, Berberich R. Cell labelling with colloidal substances in whole blood. Eur J Nucl Med 1981;6:469-72.

4. Pullman W, Hanna R, Sullivan P, Booth JA, Doe WF. Technetium-99m autologous phagocyte scanning: A new imaging technique for inflammatory bowel disease. $\mathrm{Br}$ Med J
Abscesses: The anticipated pattern of leukocyte migration into an abscess is progressive with increasing activity allowing for radioactive decay - as the granulocytes accumulate. Internal or external drainage of abscesses can, however, reverse this pattern, and drainage from an abscess into the gastrointestinal tract can give an impression of diffuse gastrointestinal inflammation. Good prognostic significance of spontaneously draining abscesses has been noted (10).

Anastomoses: After surgical anastomosis, a similar process of accumulation of granulocytes takes place in the anastomotic area. Serial studies in a group of patients in whom there was no clinical evidence of abscess formation showed that this process persisted for at least 17 days following surgery (11). In the early days after surgery, accumulation in the abdominal wound also occurred. These conditions become relevant in the investigation of a pyrexic patient after surgery for a possible intra-abdominal abscess.

Quantitating inflammation: Leukocyte scanning techniques have been used to quantitate IBD activity. This may be assessed visually by comparing the density of the abnormal activity with that of the bone marrow, liver and spleen to

1986;293:171-4.

5. Peters AM, Lavender JP, Danpure HJ, Osman S, Saverymuttu SH.

Technetium- $99 \mathrm{~m}$ autologous phagocyte scanning. Br Med ] 1986;293:450-1.

6. Roddie ME, Paters AM, Danpure HJ, et al. Inflammation: Imaging with Tc-99m HMPAO labelled leukocytes. Radiology 1988;166:767-77.

7. Peters AM, Roddie ME, Danpure HJ, et al. Tc-99m HMPAO labelled leukocytes: Comparison with In-111 tropolonate labelled granulocytes. Nucl Med Commun 1988;9:449-63.

8. Saverymuttu SH, Lavender JP, Hodgson HJF, Chadwick VS. Assessment of disease activity in inflammatory bowel disease: A new approach produce a semiquantitative 1,2 or $3+$ grading. In a comparative study on the value of this technique in colonic disease, the comparison with histological grading on tissue obtained at colonoscopy was good (8). The main value of quantitation, however, is in serial studies using paired observations in patients undergoing clinical trials. To obtain numerical data, fecal collections have been performed, and the presence of more than $2 \%$ injected radioactivity in four day fecal collections is a very sensitive assessment of the presence of disease. Although slow transit might be anticipated to introduce major variations into excretory data, in fact the majority (greater than $85 \%$ ) of excreted radioactivity appears in the feces in the first $48 \mathrm{~h}$, so the risk of error from this source is small. Much more relevant is the problem whether - particularly if patients are not in hospital - full fecal collection can be achieved. The use of a whole body excretion index, calculating the percentage of retained whole body radioactivity after five days, offers an alternative approach. Normally more than $90 \%$ of the radioactivity (allowing for decay) remains in the body after five days. In one trial this method clearly gave more valid data than that based on fecal collections (12).

using ${ }^{111}$ In granulocyte scanning. Br Med J 1983;287:1751-3.

9. Saverymuttu SH, Peters AM, Crofton $\mathrm{ME}$, et al. ${ }^{111}$ Indium granulocytes in the detection of inflammatory bowel disease. Gut 1985;26:955-60.

10. Saverymuttu SH, Peters AM, Lavender JP. Clinical importance of enteric communication with abscesses. Br Med J 1985;290:23-6.

11. Keshararzian A, Gibson R, Guest J, Spencer J, Lavender JP, Hodgson HJF. Granulocyte migration to uncomplicated intestinal anastomoses in man. Dig Dis Sci 1986;31:268-72.

12. Carpani de Kaski M, Peters AM, Lavender JP, Hodgson HJF. Oral fluticasone propionate in active Crohn's disease. Gut 1989;30:A1480. 


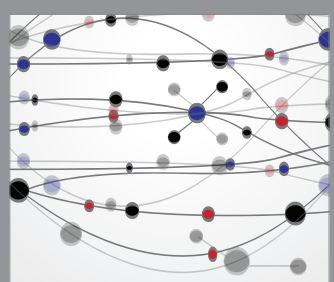

The Scientific World Journal
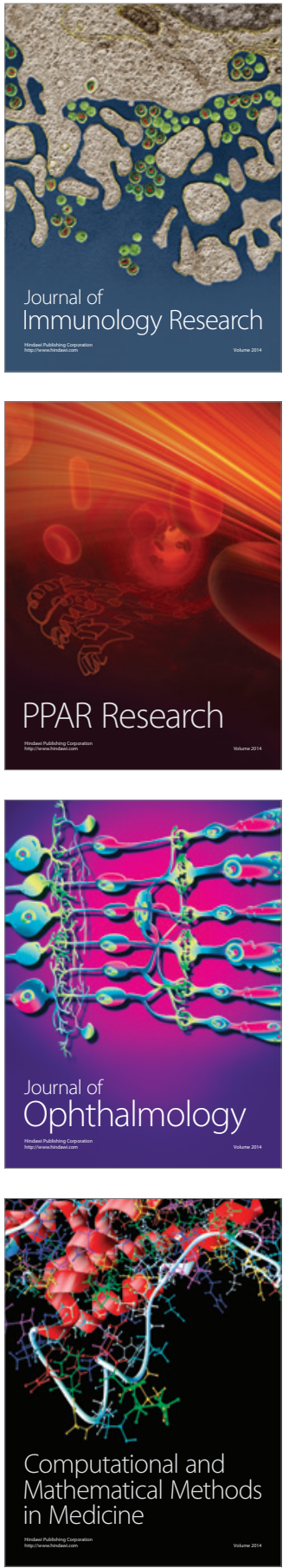

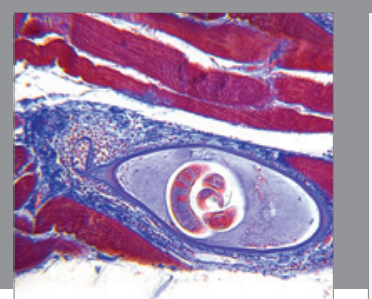

Gastroenterology Research and Practice

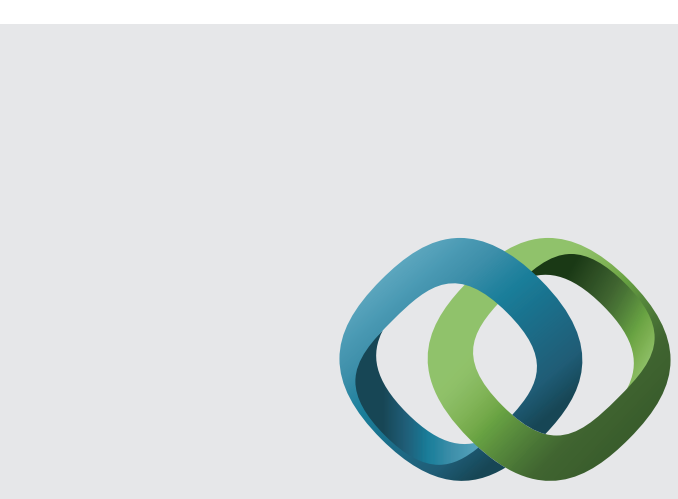

\section{Hindawi}

Submit your manuscripts at

http://www.hindawi.com
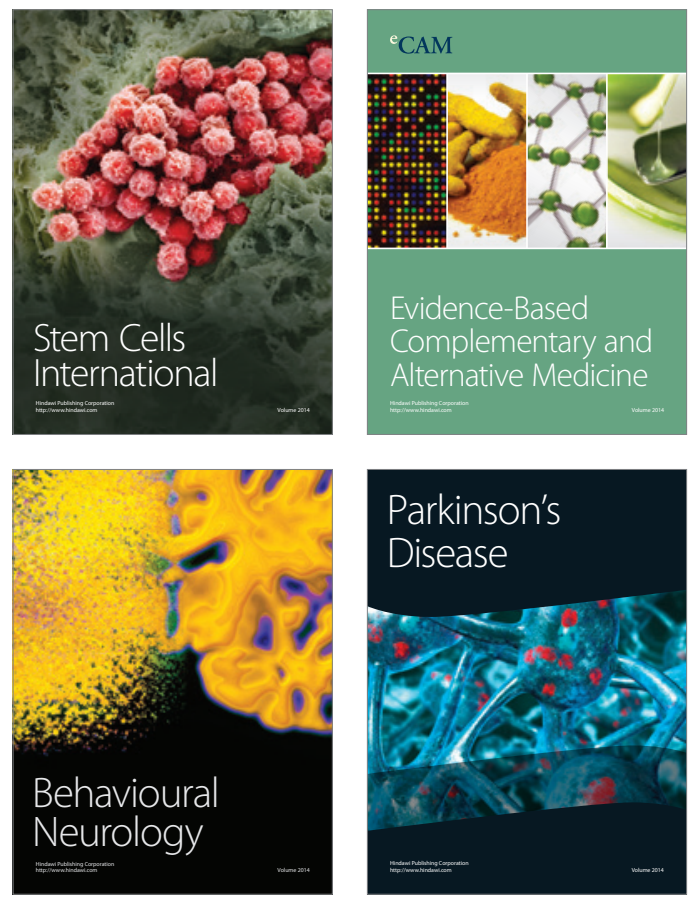
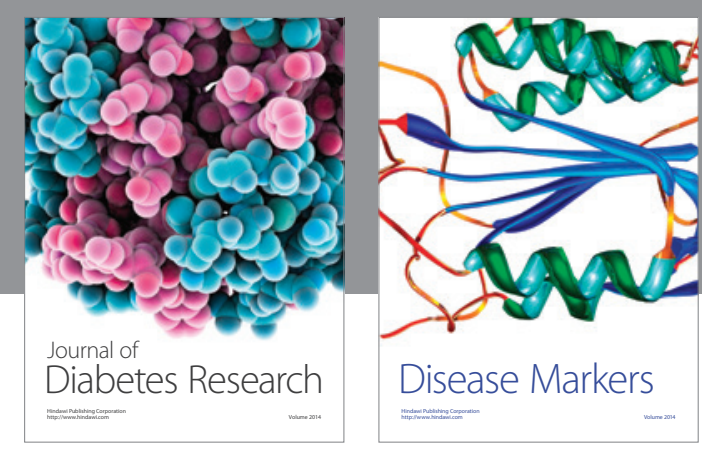

Disease Markers
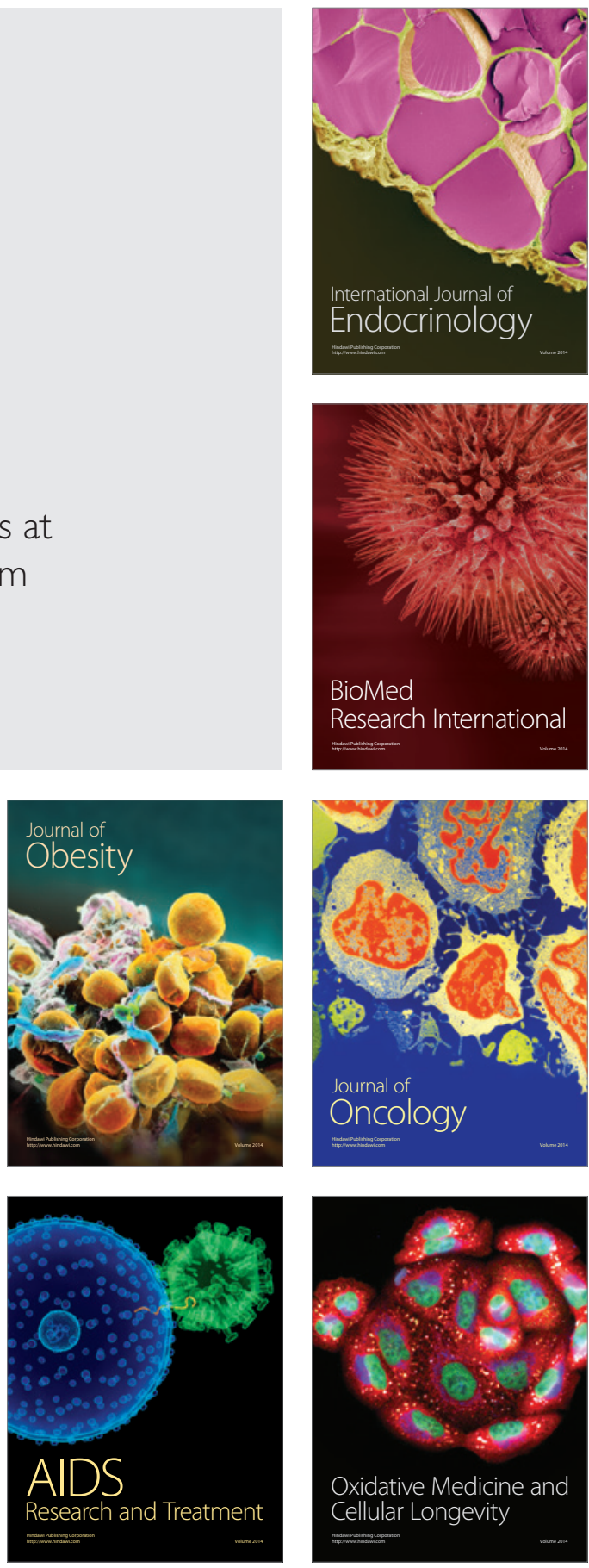